\title{
Stability Analysis of Rock Slope Surface with 3D Geomat Under Seismic and Seepage Condition
}

\author{
Wang Guangyue ${ }^{1, a}$, Chen Tingting ${ }^{1, b}$, Wang Yan $^{1, c}$ and Gao Yun ${ }^{1, d}$ \\ ${ }^{1}$ Shandong University, jinan, China \\ awgyue@sdu.edu.cn, b945211316@qq.com, 1466181153@qq.com, d414102022@qq.com
}

\begin{abstract}
Keywords:3D geomat; stability; seepage; seismic; safety factor; rivet space
Abstract. This paper discusses the mechanical stability of rock slope with 3D geonet protection system.A damaged 3D geomat slope model under seismic load and seepage condition is established. The paper studies the effect of rainwater infiltration and seismic load to the stability of 3D geomat slope surface in the process of slope greening. The stable formula of safety factor with $3 \mathrm{D}$ geomat protection system under seismic load and seepage condition and the equation of rivet space under the condition of limit equilibrium are present. Stability design diagram of rivet space is obtained based on the parameters in the equation.
\end{abstract}

\section{Introduction}

With the development of engineering construction, it is unavoidable to cut rock slope, which destroys the ecological environment, leading to bare slopes.Under the condition of strom and earthquake, it is likely to cause soil and water loss[1].The traditional slope treatment in engineering protection has a high cost as well as impacts the environment[2].Vegetation slope protection with 3D geomat, a ecological slope protection technique, adopts the combination of vegetation and 3D geomat to form a solid composite mechanical lock embedded system by vegetation root system, 3D geomat and soil. And the technique is widely used in project construction, because it can increase the soil shear strength to protect surface soil from sliding[3]. In addition, the method is helpful for vegetation restoration environmental beautification.At present, many studies concentrate on the fixing soil, anti-scouring and reinforcing effect of 3D geomat after the vegetation growing up, but there is few stability studies under rain seepage and seismic loading condition, especially in rivet design standard[4].Given that, based on the stability analyse of rock slope with 3D geomat protection system, the safety factor universal formula of protection system under seepage and seismic loading condition is deduced, and then, adopting limit equilibrium method, the relationship between rivet design and parameters is analyzed to obtain rivet design standard, which provide technical support to 3D slope protection.

\section{Stability analysis of 3D geomat}

In the early period of slope paved with 3D geomat, 3D geomat is fixed on the slope mainly by the rivet and the friction with the slope surface, because the vegetation has not grown up, and the undeveloped roots can not play a role.And the rock slope can enough anchoring force to resist deformation when the slope is paved with $3 \mathrm{D}$ geomat with the rivet embedded in the stable rock at sufficient depth. The mechanical state of the 3D geomat will be changed, when take the seismic and rainfall seepage into condition. And the change of mechanical state makes it possible that the tensile force of 3D geomat by rivet exceeds the tensile strength of 3D geomat. So a mechanical model analyzing the safe mode of 3D geomat protection system is established to discuss the distribution of rivet.

An element is taken along the slope surface for mechanical analysis. And suppose that rivets are evenly spaced in the longitudinal and transverse direction of the slope surface; the rivet space is d; the slope length is L; the self-weight of the element is G; the firction between the slope and the element is $R_{f}$; the seismic force is $F_{e}$; the seepage force in the 3D geomat is $J_{D}$; and the support of slope to 3D 
geomat is $\mathrm{F}_{\mathrm{N}}$. The stress condition is as Fig. 1 , where $\mathrm{t}$ : the thickness of $3 \mathrm{D}$ geomat, $\mathrm{t}_{\mathrm{w}}$ : the height of the water level in the planting soil, $\alpha$ : the slope angle.

The formulas of forces are as follows, and the safety factor universal formula of slope surface with $3 \mathrm{D}$ geomat is deduced.

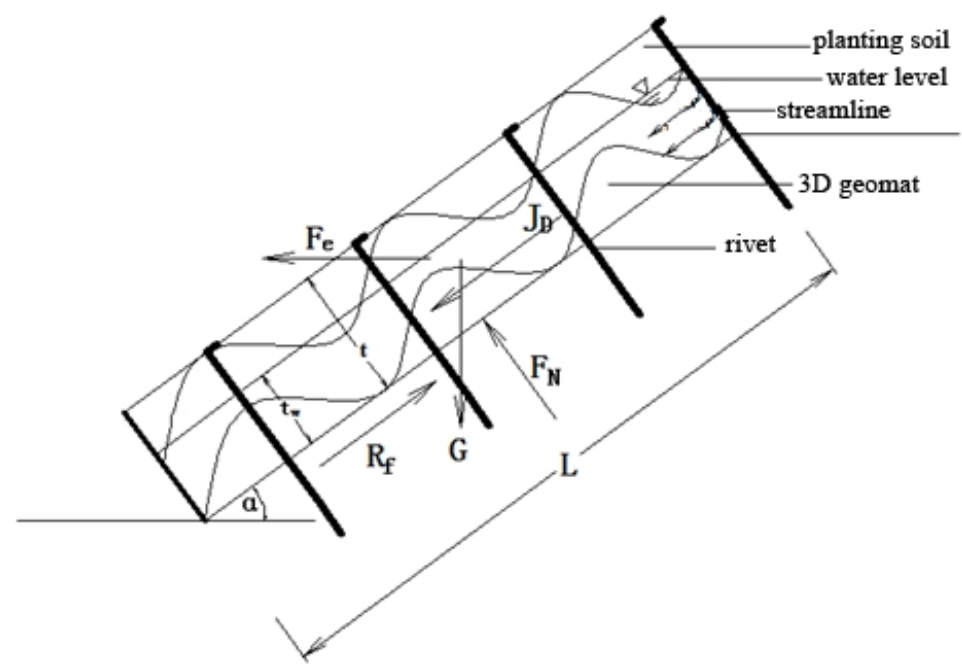

Fig. 1 the free body diagram of 3D geomat slope surface.

(1)self-weight $\mathrm{G}$

That is, the weight of $3 \mathrm{D}$ geomat protection system is the weight of filled soil.

$$
\mathrm{G}=\gamma \mathrm{Lt}+\left(\gamma_{\mathrm{sat}}-\gamma_{\mathrm{w}}-\gamma\right) \mathrm{Lt}_{\mathrm{w}} \text {. }
$$

Where $\gamma$ : the unit weight of planting soil in the 3D geomat above the waterline, $\gamma_{\text {sat }}$ : the saturated unit weight of $3 \mathrm{D}$ geomat planting soil, $\gamma_{\mathrm{w}}$ : the unit weight of water, $\mathrm{L}$ : the length of $3 \mathrm{D}$ geomat, $t$ :the thickness of 3D geomat, $t_{\mathrm{w}}$ : the height of the water in the planting soil. And the unit weight of planting soil below the waterline is the submerged unit weight.

(2)seismic force $\mathrm{F}_{\mathrm{e}}$

This paper only considers the horizontal seismic force, but ignore the vertical seismic force when analyzing the stability of 3D geomat slope surface under the condition of seismic.

$$
\mathrm{F}_{\mathrm{e}}=\mathrm{C}_{\mathrm{i}} \mathrm{C}_{\mathrm{z}} \mathrm{K}_{\mathrm{h}} \mathrm{G}
$$

Where, $C_{i}$ : the correction importance coefficient, $C_{z}$ :the synthetic influence coefficient, and $C_{z}=0.25$, $\mathrm{K}_{\mathrm{h}}$ : horizontal seismic factor . Accoring to Specification of Earthquake Resistant Design for Highway Engineering, $C_{i}=1.7$. And the Table 1 is the seismic intensity and the horizontal seismic coefficient respectively.

Table. 1 The list of values of the horizontal seismic coefficient.

\begin{tabular}{c|c|c|c}
\hline Seismic intensity & 7 & 8 & 9 \\
\hline $\mathrm{K}_{\mathrm{h}}$ & 0.1 & 0.2 & 0.4 \\
\hline
\end{tabular}

(3)the seepage force $J_{D}$

In this paper, the permeability in the slope toe is better, however, the ideal seepage direction is parallel to the slope surface[5].

$$
\mathrm{J}_{\mathrm{D}}=\mathrm{i} \gamma_{\mathrm{w}} \mathrm{Lt}_{\mathrm{w}}=\gamma_{\mathrm{w}} \mathrm{Lt}_{\mathrm{w}} \sin \alpha
$$

(4)the support $\mathrm{F}_{\mathrm{N}}$

The forces of 3D geomat protection system to slope can be devided into the component of self-weight and the component of seismic force

$$
\mathrm{F}_{\mathrm{N}}=\mathrm{G} \cos \alpha-\mathrm{F}_{\mathrm{e}} \sin \alpha
$$

(5)the friction $\mathrm{R}_{\mathrm{f}}$

$\mathrm{R}_{\mathrm{f}}=\mathrm{F}_{\mathrm{N}} \tan \varphi_{\mathrm{f}}$ 
Where, $\varphi_{\mathrm{f}}$ : the friction angle between planting soil in 3D geomat and slope interface.

Analyze the mechanics principle of the element and obtain the equilibrium equation.

$$
\mathrm{R}_{\mathrm{j}}=\mathrm{Fecos} \alpha+\mathrm{G} \sin \alpha+\mathrm{J}_{\mathrm{D}}-\mathrm{R}_{\mathrm{f}}
$$

Where, $\mathrm{R}_{\mathrm{j}}$ : the tensile force of rivet to the $3 \mathrm{D}$ geomat.

The universal formula of rivet design tensile force is obtained by substituting Eq.1 Eq.5 into Eq.6.

$$
\mathrm{R}_{\mathrm{j}}{ }^{\prime}=\left[\sin \alpha-\cos \alpha \tan \varphi_{\mathrm{f}}+\left(\cos \alpha+\sin \alpha \tan \varphi_{\mathrm{f}}\right) \mathrm{C}_{\mathrm{i}} \mathrm{C}_{\mathrm{z}} \mathrm{K}_{\mathrm{h}}\right]\left[\gamma \mathrm{Lt}+\left(\gamma_{\mathrm{sat}}-\gamma_{\mathrm{w}}-\gamma\right) \mathrm{Lt}_{\mathrm{w}}\right]+\gamma_{\mathrm{w}} \mathrm{Lt}_{\mathrm{w}} \sin \alpha
$$

The safety factor $K_{s}$ is defined as the ratio between the allowable ensile strength of $3 \mathrm{D}$ geomat and design tensile force of rivet, that is

$$
\mathrm{K}_{\mathrm{s}}=\mathrm{R}_{\mathrm{j}} / \mathrm{R}_{\mathrm{j}}
$$

Where, $\mathrm{R}_{\mathrm{j}}$ : the allowable tensile strength of $3 \mathrm{D}$ geomat, and it can be expressed as:

$$
R_{j}=t_{j} L / d^{2}
$$

Where, $\mathrm{f}_{\mathrm{j}}$ : the tensile strength per unit depth of $3 \mathrm{D}$ geomat, $\mathrm{K}_{\mathrm{j}}$ : the total reduction factor, and it takes $1.45[6]$.

The safety mode universal formula of slope surface with 3D geomat is obtained by substituting Eq.7 and Eq.9 into Eq.8:

$$
\mathrm{K}_{\mathrm{s}}=\left(\mathrm{tf}_{\mathrm{j}} \mathrm{L} / \mathrm{d}^{2} \mathrm{~K}_{\mathrm{j}}\right) /\left\{\left[\sin \alpha-\cos \alpha \tan \varphi_{\mathrm{f}}+\left(\cos \alpha+\sin \alpha \tan \varphi_{\mathrm{f}}\right) \mathrm{C}_{\mathrm{i}} \mathrm{C}_{\mathrm{z}} \mathrm{K}_{\mathrm{h}}\right]\left[\gamma \mathrm{Lt}+\left(\gamma_{\mathrm{sat}}-\gamma_{\mathrm{w}}-\gamma\right) \mathrm{Lt}_{\mathrm{w}}\right]+\gamma_{\mathrm{w}} \mathrm{Lt}_{\mathrm{w}} \sin \alpha\right\}
$$

The Eq.10 is the safety factor universal formula of slope surface under the condition of seismic and rainfall seepage.

\section{Rivet space design of 3D geomat}

The rivet space is crucial to the stability of 3D geomat, which is the rivet space design issue. Analyze the stability of 3D geomat under the condition of seismic and rainfall seepage, which provides evidence for rivet space design.

Taking the limiting equilibrium condition, which means $K_{s}=1$, we obtain the following equation by Eq.10:

$$
\mathrm{f}_{\mathrm{j}} / \mathrm{rd}^{2} \mathrm{~K}_{\mathrm{j}}=\left(\gamma_{\mathrm{w}} / \gamma\right) \mathrm{n} \sin \alpha+\left[1+\mathrm{n}\left(\gamma_{\mathrm{sat}} / \gamma-\gamma_{\mathrm{w}} / \gamma-1\right)\right]\left[\sin \alpha-\cos \alpha \tan \varphi_{\mathrm{f}}+\left(\cos \alpha+\sin \alpha \tan \varphi_{\mathrm{f}}\right) \mathrm{C}_{\mathrm{i}} \mathrm{C}_{\mathrm{z}} \mathrm{K}_{\mathrm{h}}\right]
$$

Where, $n$ :infiltration ratio, and $n=t_{w} / t$. $S$ is defined as safety number, and $S=f_{j} / \gamma d^{2} K_{j}$. At the same time, the larger the $S$ is, the safer the 3D geomat slope surface is. And the following four conditions should be considered: (1)no seismic and no seepage; (2)seismic and no seepage; (3)no seismic and seepage; (4)seismic and seepage. And the corresponding equation of safety number are given to draw the safety number-rivet space relationship diagram, which provides evidence for rivet space design.

(1) under the condition of no seismic and no seepage, $K_{h}=0, n=0$, and the Eq. 11 can be described as:

$$
\mathrm{S}=\sin \alpha-\cos \alpha \tan \varphi_{\mathrm{f}}
$$

According to Eq.12, the rivet space design relationship diagram with slope angle as abscissas and safety number as ordinate under the condition of no seismic and no seepage is as Fig.2.

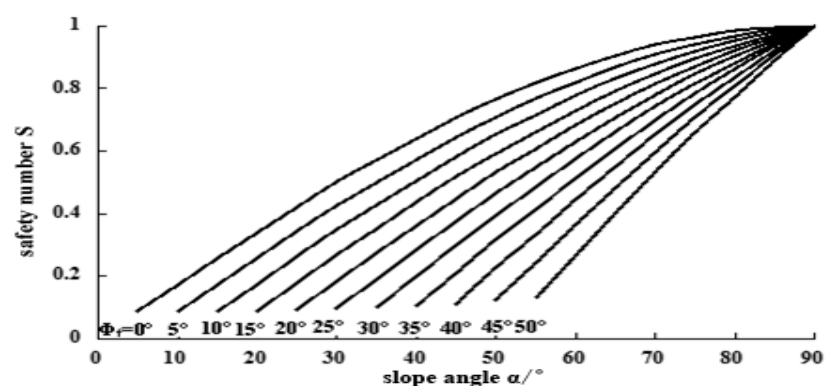

Fig.2. the rivet space design relationship diagram under the condition of no seismic and no seepage

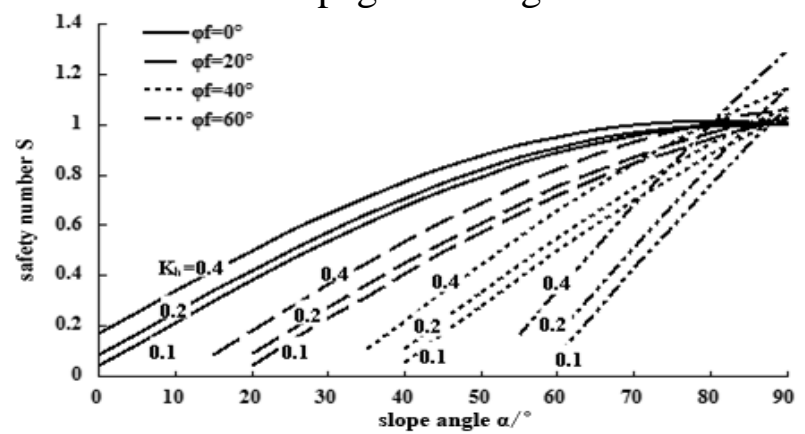

Fig.3. the rivet space design relationship diagram under the condition of seismic and no seepage. 
(2) under the condition of seismic and no seepage, $n=0$, and the Eq.11 can be described as:

$$
\mathrm{S}=\sin \alpha-\cos \alpha \tan \varphi_{\mathrm{f}}+\left(\cos \alpha+\sin \alpha \tan \varphi_{\mathrm{f}}\right) \mathrm{C}_{\mathrm{i}} \mathrm{C}_{\mathrm{z}} \mathrm{K}_{\mathrm{h}}
$$

According to Eq.13, the rivet space design relationship diagram with slope angle as abscissas and safety number as ordinate under the condition of seismic and no seepage is as Fig.3.

(3) under the condition of no seismic and seepage paralleling to $3 \mathrm{D}$ geomat surface, $K_{h}=0, n=0$, that is, $\mathrm{t}_{\mathrm{w}}=\mathrm{t}$, and the Eq.11 can be described as:

$$
\mathrm{S}=\mathrm{f}_{\mathrm{j}} / \gamma_{\mathrm{sat}} \mathrm{d}^{2} \mathrm{~K}_{\mathrm{j}}=\sin \alpha \gamma_{\mathrm{w}} / \gamma_{\mathrm{sat}}+\left(1-\gamma_{\mathrm{w}} / \gamma_{\mathrm{sat}}\right)\left(\sin \alpha-\cos \alpha \tan \varphi_{\mathrm{f}}\right)
$$

According to the saturated unit weight of general soil, the value of $\gamma_{\mathrm{w}} / \gamma_{\text {sat }}$ can be approximated to 0.5[9], and the Eq.14 can be described as:

$$
\mathrm{S}=\mathrm{f}_{\mathrm{j}} / \gamma_{\mathrm{sat}} \mathrm{d}^{2} \mathrm{~K}_{\mathrm{j}}=0.5 \sin \alpha+0.5\left(\sin \alpha-\cos \alpha \tan \varphi_{\mathrm{f}}\right)
$$

According to Eq.15, the rivet space design relationship diagram with slope angle as abscissas and safety number as ordinate under the condition of no seismic and seepage is as Fig.5.

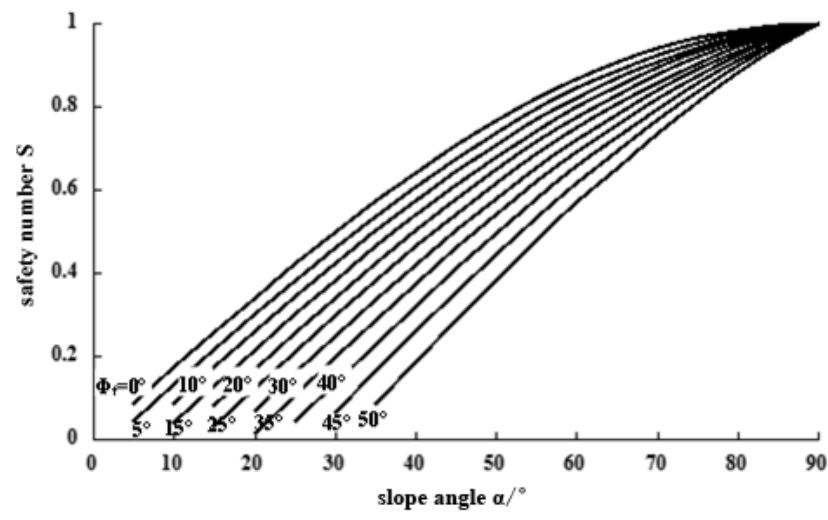

Fig.4. the rivet space design relationship diagram under the condition of no seismic and seepage paralleling to $3 \mathrm{D}$ geomat surface $(\mathrm{n}=1)$.

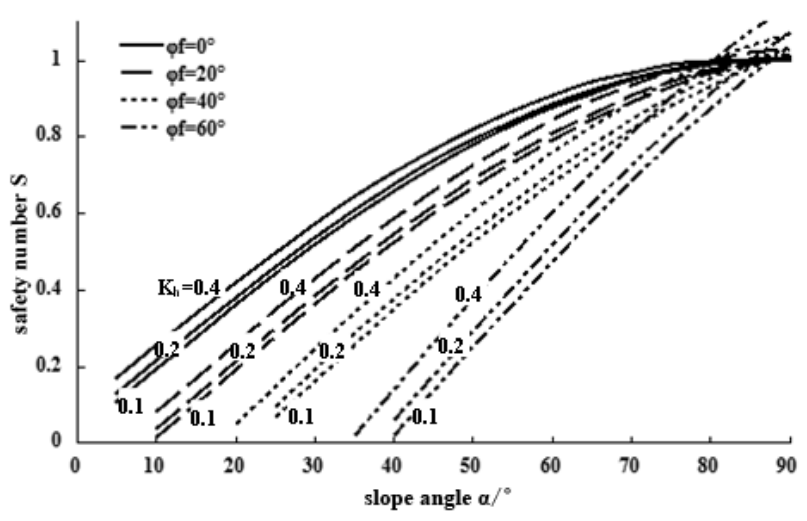

Fig.5. the rivet space design relationship diagram under the condition of seismic and seepage paralleling to $3 \mathrm{D}$ geomat surface $(\mathrm{n}=1)$.

(4) under the condition of seismic and seepage paralleling to $3 \mathrm{D}$ geomat surface, $n=1$, that is, $t_{w}=t$ and the Eq.11 can be described as:

$$
\mathrm{S}=\mathrm{f}_{\mathrm{j}} / \gamma_{\mathrm{sat}} \mathrm{d}^{2} \mathrm{~K}_{\mathrm{j}}=\sin \alpha \gamma_{\mathrm{w}} / \gamma_{\mathrm{sat}}+\left(1-\gamma_{\mathrm{w}} / \gamma_{\mathrm{sat}}\right)\left(\sin \alpha-\cos \alpha \tan \varphi_{\mathrm{f}}+\left(\cos \alpha+\sin \alpha \tan \varphi_{\mathrm{f}}\right) \mathrm{C}_{\mathrm{i}} \mathrm{C}_{\mathrm{z}} \mathrm{K}_{\mathrm{h}}\right)
$$

The value of $\gamma_{\mathrm{w}} / \gamma_{\mathrm{sat}}$ can be approximated to 0.5 , and the Eq.16 can be described as:

$$
S=f_{j} / \gamma_{s a t} d^{2} K_{j}=0.5 \sin \alpha+0.5\left(\sin \alpha-\cos \alpha \tan \varphi_{f}+\left(\cos \alpha+\sin \alpha \tan \varphi_{f}\right) C_{i} C_{z} K_{h}\right)
$$

According to Eq.17, the rivet space design relationship diagram with slope angle as abscissas and safety number as ordinate under the condition of seismic and seepage paralleling to 3D geomat surface is as Fig.5.

\section{Conclusions}

(1)The failure mode is that the tensile force by rivet for resisting sliding exceeds the tensile strength of 3D geomat, leading to the 3D geomat damage and causing the protection system failure when the rock slope surface is paved with $3 \mathrm{D}$ geomat. 
(2)Define that the safety factor is the ratio between the tensile strength of 3D geomat and the designed rivet tensile force, and the stability of protection system can be evaluated according to the safety factor universal formula of protection system under the condition of seismic and seepage.

(3)Based on limiting equilibrium condition, we can deduce the rivet space design universal formula by the safety factor universal formula to drew the diagram. According to the diagram and parameters of slope, the biggest rivet space under the limiting equilibrium condition can be obtained to offer the design standard for the application of 3D geomat.

\section{Acknowledgements}

This work was financially supported by the National Natural Science Foundation of China (11372165).

\section{References}

[1]W.N. Xue,T.Q. Wang, and J.J. Ye:Water Resources and Hydropower Engineering Vol.33(1992),p.35 36,40

[2]Y. Wang,C.L. Long,and Y.T. Liu:Research of Soil and Water Conservation Vol.12(2005),p.199 202

[3]X.L. Liu,Q. Gao and H.L. Xiao:Journal of Yangtze River Scientific Research Institute Vol.25(2008),p.58 61

[4]X.W. Zhang,and R.X. Huang:Highways and Automotive Applications(2003),p.32 33

[5]J.J. Yang,L. Wang,and J.G. Deng:Chinese Journal of Rockmechanics and Engineering Vol.25(2006),p.42

[6]H.L. Xiao,Z. Wang,and J.F. Zhang:Rock and Mechanics Vol.25(2004),p.1800 1804 